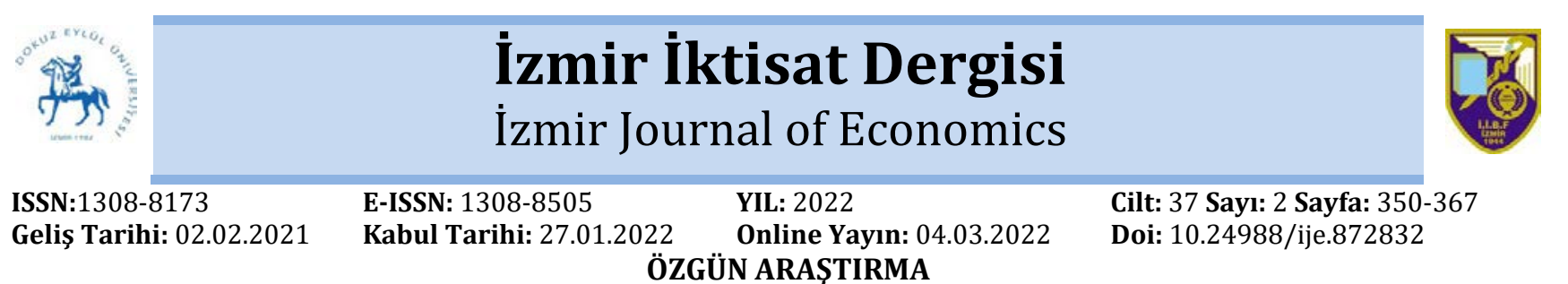

\title{
Gelişmekte Olan Ülkelerde Net İşletme Sermayesi Yönetiminin Firma Karlılığı Üzerine Etkisi: Hiyerarşik Model Yaklaşımı
}

\author{
Sema TURAN ${ }^{1}$, Rümeysa BiLGIN ${ }^{2}$ \\ Özet
}

Bu araştırmada 2005-2018 yıllarında 39 ülkeden 142727 finans dışı sektörde faaliyet gösteren halka açık firmalardan oluşan geniş bir veri seti kullanılarak net işletme sermayesinin firma karlılı̆ı üzerindeki etkisi incelenmiștir. Kullanılan panel veri seti ülke, firma ve zaman olmak üzere üç düzeyli hiyerarșik bir yapıda düșünülmüștür. Bu nedenle gelișmekte olan ülkelerdeki firma karlılığı belirleyicileri Hiyerarșik Lineer Model (HLM) yaklaşımı kullanılarak analiz edilmiștir. Analiz sonucunda firma karlılı̆ındaki değişkenliğin büyük bir kısmının firma ve zaman düzeylerinden kaynaklandığı ortaya konmuştur. Ancak ülke düzeyindeki değişkenliğin küçük olması ülkeye özgü değişkenliğin firma karlılı̆ı üzerinde etkisinin olmadığı şeklinde yorumlanmamalıdır. Sonuç olarak gelişmekte olan ülkelerde faaliyet gösteren firmaların yöneticileri net işletme sermayesi kararlarını verirken bu kararın firma karlılığını doğrudan etkileyeceğini dikkate almalıdırlar.

Anahtar kelimeler: Firma karlılığı, net işletme sermayesi yönetimi, hiyerarşik lineer model Jel Kodu: G30, L25, M21

\section{The Effect Of Net Working Capital Management To Profitability In Developing Countries: Herarchical Model Approach}

\begin{abstract}
In this study, the effect of net working capital on firm profitability was investigated by using a large data set which consist of 142727 publicly traded non-financial firms from 39 countries in 2005-2018. The panel dataset used was considered in a three-level hierarchical structure: country, firm and time. Therefore, determinants of firm profitability in developing countries were analyzed using the Hierarchical Linear Model (HLM) approach. As a result of the analysis, it was revealed that most of the variability in firm profitability originated from firm and time levels. However, small variability at the country level should not be interpreted as country-specific variability has no effect on firm profitability. Therefore, the managers of firms operating in developing countries should take into account that their net working capital decisions will directly affect the firm profitability.
\end{abstract}

Keywords: Firm profitability, net working capital management, hierarchical linear model Jel Codes: G30, L25, M21

ATIF ÖNERİsí (APA): Turan, S., Bilgin, R. (2022)). Gelişmekte Olan Ülkelerde Net İşletme Sermayesi Yönetiminin Firma Karlılığı Üzerine Etkisi: Hiyerarşik Model Yaklaşımı. İzmir Íktisat Dergisi. 37(2). 350-367. Doi: 10.24988/ije.872832

1 Yüksek Lisans Öğrencisi, İstanbul Sabahattin Zaim Üniversitesi, Sosyal Bilimler Enstitüsü, İşletme Yönetimi Bölümü, Küçükçekmece / İstanbul, Türkiye EMAIL: sematrnnn@outlook.com ORCID: 0000-0003-0247-4106

2 Dr. Öğr. Üyesi, İstanbul Sabahattin Zaim Üniversitesi, İşletme ve Yönetim Bilimleri Fakültesi, İşletme Bölümü, Küçükçekmece / İstanbul, Türkiye EMAIL: rumeysa.bilgin@izu.edu.tr ORCID: 0000-0002-5919-0035 


\section{GíRiş}

Günümüzde değișen ekonomik koșullar ile birlikte artan rekabet ortamında, firmalar stratejik kararlarını verirken karlılık, risk ve likidite durumlarını göz önünde bulundurmalıdırlar (Aydın vd., 2015; Kindik ve Aslan, 2017). Firmaların verdikleri yatırım ve finansman kararları sonucunda katlandıkları riskler karlılığı yakından etkilemektedir. Bu nedenle faaliyetlerini sürdürürken likidite ve karlılık arasında denge kurmayı amaçlarlar (Küçükaraba, 2012). Alınan stratejik kararlar da risk ile karlılık arasında oluşturulan dengenin bir sonucudur. (Block ve Hirt, 2005). Yatırımclar açısından, alınan riski karşılamak için elde edilecek getirinin sermaye maliyetinden daha fazla olması amaçlanır. Getiri ile risk faktörleri gelecekteki firma değerini de etkilemektedir (Akgüç, 2013). Son yıllarda zorlaşan rekabet koşulları, kısa vadeli yatırımların firmanın başarısı açısından hayati öneme sahip olmasına yol açmıştır. İşletme sermayesi yönetimi firma karlılığı açısından da oldukça önemlidir (Yazdanfar ve Öhman, 2014). Likidite, firmaların faaliyet süreci içerisinde oluşabilecek aksaklıklar sonucunda kısa vadeli yükümlülüklerini yerine getirebilmelerini sağlar (Padachi, 2006). İşletme sermayesi dinamik bir yapıya sahip olduğundan likidite esasına göre söz konusu varlıklara yapılan yatırım tutarı ve finanse edilmesi firmalar için önem taşımaktadır (Korkmaz ve Ceylan, 2011).

İşletme sermayesi, firmaların faaliyetlerini sürdürürken bir hesap dönemi içinde likide çevrilebilen sermayedir (Akgüç, 2013). Cari varlıkların toplam varlıklar içerisindeki payı ne olursa olsun, çeşitli işletme sermayesi bileşenlerinin bulunması, birbiriyle ilişki içinde olmaları ve günlük faaliyetlerdeki işlevleri işletme sermayesi yönetiminde önemli bir rol oynamaktadır. Firmaların bu varlıklara fon bağlaması kaçınılmazdır. Cari varlıkların uzun vadeli sermaye tarafından finanse edilen kısmı ise net işletme sermayesini oluşturur. Net işletme sermayesi, firmaların vadesi gelen yükümlülüklerini karşılayabilme göstergelerindendir (Caballero vd., 2014). Başarılı bir net işletme sermayesi yönetimi yatırım ve finansman kararlarının doğru alınmasına bağlıdır. Firmalar, net işletme sermayesi yönetim stratejilerini ne zaman ve ne kadar likite ihtiyaç duyulacağı ve bu miktarın nasıl temin edileceği konusundaki tahminlemeler ile belirlerler. Optimum düzeyde net işletme sermayesi yatırımı yapan firmalar, kaynaklarını uzun vadeli varlıklara yatırarak daha yüksek getiri elde etme imkânına kavuşurlar (Okka, 2010).

Firmaların net işletme sermayesine yapacakları yatırımlar ve kullanılan fon kaynakları, gelecekte beklenen risk ve getiriye göre şekillenir (Martin, 2014). Cari varlıkların finansmanında tercih edilen yaklaşımlara göre üç alternatif yatırım ve finansman stratejisinden söz edilebilir. İhtiyatlı (tutuk) işletme sermayesi stratejisi, cari varlıklara yapılan yatırımın en üst düzeyde olduğu stratejidir. Likiditesi yüksek firmaların borçlarını ödeyememe riskinin oldukça düşük olması yüzünden ihtiyatlı olarak nitelenen bu strateji daha çok küçük ölçekli firmalar tarafından tercih edilmektedir. Küçük firmaların sabit varlık yatırımlarını kiralayarak sınırlamaları söz konusuyken, cari varlık yatırımlarını azaltmak için alternatifleri yoktur. Bu firmaların, sermaye piyasasından fon oluşturma kapasiteleri de düşük olduğu için daha çok kısa vadeli finansmana ağırlık verirler. Dolayısıyla işletme sermayesi, küçük firmalar açısından daha önemlidir (Dağll, 2013). Buna ek olarak, tüm firmalar enflasyonun arttığı dönemlerde genellikle firmalar daha fazla işletme sermayesine ihtiyaç duyarlar (Aydın vd., 2015). Satışların istikrarsız olduğu durumlarda da firmaların likidite ihtiyacı artar. Böyle bir ortamda, cari varlıkların toplam varlıklara oranı yüksek olduğu bu firmalarda gevşek kredi ve tahsilat uygulamalarında artış yaşanacaktır. Bu firmaların net işletme sermayesi finansman stratejilerinde ise kısa vadeli fon kaynaklarına oldukça az başvurulur. Hem sabit varlıklarda hem de cari varlıkların sürekli ve değişken kısımları için çoğunlukla uzun vadeli fon kaynakları kullanılır. Genellikle sadece cari varlıkların oldukça değişken kısımlarına ait gereksinimler için yalnızca kısa vadeli borç kaynaklarına başvurulur. Nakit çevrim süresi uzun olan stratejide faiz giderleri fazlayken risk ve getirisi de oldukça düşüktür (Akgüç, 2013; Dağll, 2013). 
Cari varlıklar ve sabit varlıklar arasındaki dengenin sağlanmasına önem veren diğer bir strateji ise dengeli (vade uyumlu) strateji yaklaşımıdır. Vade uyumunda, varlıklar ile yükümlülükleri vadelerine bağlı olarak denkleștirmek esastır. Stokların finansmanında kısa vadeli fon kullanan firmalar satış hacimlerinin yavaş olması durumunda borçlarını ödemekte zorlanırlar. Bu nedenle firmalar devamlı sermaye ile varlıklarını karşılamak zorunda kalırlar. Ancak iktisadi varlıkların ömrünün tam olarak bilinememesi nedeniyle bu stratejinin uygulanabilirliği zordur (Korkmaz ve Ceylan, 2011).

Atılgan (atak) stratejisinin uygulandığı firmalarda ise likidite daha sınırlı düzeydedir. Nakit ve menkul kıymetler, ticari alacak ve stoklar daha sınırlı olduğundan işletme sermayesi yatırımları da daha azdır. Söz konusu varlıklara yapılan yatırım azaldıkça etkinlik arttığından dolayı nakde çevrim süresi kısalır. Sıkı kredi ve tahsilat uygulandığından ticari alacak ve stoklara yapılan yatırım nispeten daha azdır. Bu nedenle firmaların bulundurma maliyetiyle birlikte giderleri de azalacaktır (Kayahan, 2014). Firmalar kısa vadeli fon kaynakları ile cari varlıkların sabit kısmının bir bölümünü esnek şekillerde finanse edebilirler. Kısa vadeli fon kaynakları uzun vadeli kaynaklara göre daha esnektir. $\mathrm{Bu}$ firmalarda faiz giderleri daha düşüktür. Kısa vadeli fonlamada firmalar borçlarını geri ödemede veya yenilemede gereksinim duyduğu kaynaklar için yüksek bir faiz ödemek zorunda kalmazlar. Sabit varlıklarda kısa vadeli fon kaynakları kullanıldığında finansal risk de artacaktır. Nakde dönüşme süresi kısa olduğundan beklenen getirisi de daha fazladır (Korkmaz ve Ceylan, 2011).

Net işletme sermayesi yatırımlarında alınan kararlarda firmalar kendileri için en uygun yapıyı oluşturmaya çalışırlar. Söz konusu varlıkların toplam varlık içerisindeki oranı ne olursa olsun, bu varlıkların çeşitlendirilmesinin ve birbirleriyle ilişkili olmasının firma karlılığı için oldukça önemli olduğu düşünülmektedir. (Akgüç, 2013).

$\mathrm{Bu}$ çalışma, gelişmekte olan ülkelerde net işletme sermayesinin firma karlılığı ile ilişkili olup olmadığını sorusuna cevap aramaktadır. 2005-2018 dönemleri arasında 39 gelişmekte olan ülkeden 142727 adet firmanın karlılıklarını etkileyen ülkeye ve firmaya özgü faktörler Hiyerarşik Lineer Model (HLM) yaklaşımı kullanılarak araştırılmıştır. Analiz sonucunda net işletme sermayesi yönetiminin firma karlılı̆̆ı üzerinde etkili olduğu bulgulanmıştır.

Çalışma beş bölümden oluşmaktadır. İkinci bölümde net işletme sermayesi ve firma karlılığı ilişkisi ile ilgili literatürde yer alan çalışmalardan bahsedilmiştir. Üçüncü bölümde çalışmada kullanılan veri seti ve uygulanan ekonometrik metot detaylı olarak açıklanmıștır. Dördüncü bölümde ise analiz sonucunda elde edilen bulgulara yer verilmiştir. Çalışma 5 . ve son bölüm olan sonuç ve tartışma bölümü ile sonlandırılmıştır.

\section{LITERATÜR}

Kurumsal finans alanında net işletme sermayesi ilgili bir birçok teorik ve ampirik çalışma yapılmış ve oldukça zengin bir literatür ortaya çıkmıștır (Wang, 2002; Afza ve Nazir, 2008; Caballero vd., 2014; Raheman vd., 2010; Panigrahi, 2013; Yazdanfar ve Öhman, 2014). Bu çalışmalar incelendiğinde net çalışma sermayesinin firma karlılığına etkisi, sermaye harcamaları ile ilişkisi, belirleyicileri ve likidite ile karlılık arasındaki dengeleme sürecindeki rolü literatürde en çok araştırılan konular olarak öne çıkmaktadır (Prasad vd., 2019). Bazı çalışmalarda, tedarik maliyetini düşürmek, girdi fiyatlarındaki dalgalanmalara karşı korunma sağlamak ve stokta ürün kalmamasının neden olduğu satış kaybını en aza indirmek için daha fazla stok tutmanın işletme sermayesine daha fazla yatırım yapılmasına neden olduğu gözlemlenmiştir (Çakır, 2013; Şahin, 2011; Korkmaz ve Karaca, 2014; Doğan ve Elitaş, 2014; Demireli vd., 2014; Çakır ve Küçükkaplan, 2012). Bunların yanı sıra firmalar satışları ve böylece karlılığı artırarak firma büyümesinin sağlanmasını amaçlarlar. Firma karlılığı ve net işletme sermayesi ilişkisini inceleyen çalışmalarda etkin bir net işletme sermayesi yönetimi ile karlılığın artacağı ortaya konmuştur (Coşkun ve Kök, 2011; Aygün, 2012; Akbulut, 2011; Aytürk ve Yanık, 2015; Aktas vd., 2015; Özçalık ve Aytekin, 2017; Padachi, 2006). 
Belçika örneğinde net işletme sermayesi ve karlılık ilişkisini inceleyen Deloof (2003) nakit çevrim süresi ile firma karlılığı arasında ters yönlü bir ilişki bulgulamıştır. Bu sonuçlara göre, özellikle alacak tahsil süresinin ve stokta kalma süresinin optimal bir düzeye indirilmesi firma karlılı̆̆ını arttırmaktadır. Wang (2002) çalışmasında Japonya ve Tayvan'daki firmalar için likidite yönetimi ile kurumsal karlılık arasındaki ilişkiyi incelemiştir. Genel olarak, bulgular atılgan net işletme sermayesi yönetiminin işletme performansını artırdığını göstermektedir. Afza ve Nazir (2008) 1998-2003 dönemi için Karaçi Menkul Kıymetler Borsası'nda faaliyet gösteren halka açık firmaların atılgan işletme sermayesi politikaları arasındaki ilişkiyi incelemişlerdir. Firmaların karlılık ölçümleri ile işletme sermayesi yatırımlarının atılgan işletme sermayesi derecesi ve finansman politikaları arasında ters yönlü bir ilişki tespit edilmiştir.

Caballero vd. (2014), finans sektörü dışındaki İngiliz firmalarının çalışma sermayesi yönetimi ile firma karlılığı arasındaki ilişkisini araştırmışlardır. Araștırmanın sonucuna göre çalışma sermayesi ile firma karlılığı arasında kuvvetli bir ilişki olduğu tespit edilmiştir. Bu ilişkinin başarılı bir şekilde yönetilmesi maliyetleri ve getiriyi dengeleyen, firma değerini maksimize eden optimal bir çalışma sermayesi ile mümkün olmaktadır. Finansal kısıtlamaların olduğu firmalarda optimal çalışma sermayesinin seviyesi daha düşük olarak gözlemlenmiştir. Bhatia ve Srivastava (2016) çalışmalarında, işletme sermayesi yönetimi ile Hindistan'daki ilaç şirketlerinin karlılığı arasındaki temel ilişkiyi incelemişlerdir. Etkin işletme sermayesi yönetimi ile firmaların karlılığı ve likidite pozisyonunu güçlendirebileceği, böylece firmanın piyasa değerini artacağ gözlemlenmiştir.

Raheman vd. (2010), Pakistan'daki firmaların işletme sermayesi yönetiminin firma performansı üzerindeki etkisini analiz etmeyi amaçlamıştır. Pakistan'daki firmaların ihtiyatlı işletme sermayesi yönetimi politikasını izledikleri ve firmaların tahsilat ve ödeme politikalarını yoğunlaştırmaları ve geliștirmeleri gerektiği sonucuna ulaşılmıştır. Yine Pakistan'da Raheman ve Nasr (2007) tarafından yapılan bir çalışmada işletme sermayesi yönetimi değişkenleri ile firma karlılığı arasında güçlü bir negatif ilişki olduğunu görülmüştür. Bulgulara göre nakit dönüşüm döngüsü arttıkça firmanın kârlılığının azalmasına yol açacaktır. Bu nedenle, yöneticiler nakit dönüşüm döngüsünü olabilecek en düşük seviyeye düşürerek hissedarlar için pozitif bir değer oluşturabilecektir. Bu çalışmalar, Pakistan gibi gelişmekte olan bir pazarda işletme sermayesi yönetimi politikalarının daha iyi anlaşılmasına katkıda bulunmuştur.

Panigrahi (2013), negatif işletme sermayesi ve kârlılığı üzerindeki etkisi konusunu araştırmıștır. Negatif işletme sermayesi iflas tehlikesi gibi algılanmaktadır. Ancak bu çalışmada, piyasada iyi bir imaja ve alacaklılarıyla iyi bir ilişkiye sahip olan firmaların negatif işletme sermayesinden faydalanabileceği ortaya konmuştur. Buna ek olarak, işletme sermayesi ile kârlılık arasında pozitif bir ilişki olsa da, bu durumun her şart altında geçerli olmadığı gözlemlenmiştir. Öz ve Güngör (2007), 1992-2005 yılları arasında İstanbul Menkul Kıymetler Borsası (İMKB)'nda imalat sektöründe faaliyet gösteren 68 firmanın işletme sermayesinin risk ve firma karlılığı üzerinde etkilerini incelemişlerdir. Firmaların net ticaret süresini kısaltarak işletme sermayesi etkinliği sağlandığında ve finansman ihtiyacını azaltabildiklerinde karlarını arttırabilecekleri ortaya konmuştur.

Yazdanfar ve Öhman (2014), nakit dönüşüm döngüsünün 2008-2011 döneminde İsveç küçük ve orta ölçekli işletmelerinde (KOBİ) karlılık üzerindeki etkisini incelemiştir. Sonuçlara göre, firmalar nakit çevrim sürelerini azaltarak ek firma değeri yarattıklarında, karlılıkları da artmaktadır. Altaf ve Shah (2017), Hindistan'da, finans dișı sektörde faaliyet gösteren firmaların işletme sermayesi yönetimi ile firma performansı arasındaki ilişkiyi incelemiştir. Çalışmanın sonuçları, işletme sermayesi yönetimi ile firma performansı arasındaki ters U-şeklindeki ilişkiyi doğrulamaktadır. Bhunia ve Das (2015)'ın yaptıkları çalışmada etkin işletme sermayesi yönetimi ile firmaların karlılığını ve likidite pozisyonunu güçlendirerek firmanın piyasa değerini artırabileceğini bulgulamışlardır. 
Hue, Chen, Ong ve Boon (2017), Malezya'da faaliyet gösteren imalat firmalarının işletme sermayesi yatırım ve finansman politikaları ile firmaların karlılığı arasındaki ilişkiyi incelemişlerdir. Firmaların brüt faaliyet gelirinin yatırım politikalarının atılganlık derecesi ile ters ilişkili olduğu, ancak finansman politikalarının atılganlık derecesi ile doğrusal yönlü bir ilişkinin var olduğu gözlemlenmiştir. Ayrıca nakit çevrim döngüsünün brüt faaliyet geliri ile olumlu bir ilişkisinin olduğu da bulgulanmıștır. Daha fazla işletme sermayesi, satış hacmi artan firmaların ticari alacaklarını tahsil etme sürelerini kısalttıklarında karlılığı artacaktır. Ancak daha yüksek işletme sermayesi seviyeleri finansman gerektirir ve sonuç olarak firmalar iflas etme olasılıklarını artıran ek finansman giderleri ile karşı karşıya kalırlar.

Ponsian vd. (2014), işletme sermayesi yönetiminin firma kârlılığı üzerindeki etkisini ortaya koymayı amaçlamışlardır. Nakit dönüşüm döngüsü arttıkça, firmanın karlılığında bir artışa yol açacağı ve yöneticilerin nakit dönüşüm döngüsünü makul bir seviyeye yükselterek hissedarlar için pozitif bir değer yaratabilecekleri saptanmiștır.

\section{VERI SETİ VE EKONOMETRIKK METOT 3.1. Veri Seti}

Çalışmanın veri setini oluşturmak için Dünya Bankası tarafından gelir düzeyi dikkate alınarak yapılan ülke sınıflandırmasına göre orta gelir grubunda yer alan ülkeler belirlenmiştir. Gelișmekte olan ülkeler olarak isimlendirilen bu ülkeler arasında Compustat Global Capital IQ veri tabanında verilerine ulaşılabilenler çalışma kapsamına dâhil edilmiştir. Compustat Global Capital IQ dünyanın farklı ülkelerinde faaliyet gösteren halka açık firmaların finansal verilerini içeren oldukça geniş bir veri bankasıdır. Ancak diğer küresel veri bankalarında da olduğu gibi bu veri setinde de, gelişmekte olan ülkelerde faaliyet gösteren firmalara ait veriler gelişmiş ülke verileri ile kıyaslandığında oldukça azdır. Firma düzeyinde verilerine ulaşılabilen 39 gelişmekte olan ülkeden toplam 142727 halka açık firma çalışmaya dâhil edilmiştir. Çalışmanın periyodu yine geçmiş yıllara ait verilere ulaşılamaması yüzünden ise 2005-2018 yılları olarak belirlenmiştir. Compustat Global Capital IQ veri tabanından çekilen firmaya özgü verilere ek olarak Dünya Bankası Dünya Gelişmişlik Göstergeleri veri setinden alınan ülkeye özgü bir dizi değişken de çalışmada kullanılmıştır.

Oluşturulan panel veri seti ülkeler, firmalar ve zaman düzeyleri olarak hiyerarşik yapı olarak düşünülmüştür. Bu hiyerarşik yapının modellenmesi için üç aşamalı çok düzeyli (hiyerarşik) bir model kurulmuştur. Modelin ilk düzeyini ülkeler oluşturmaktadır. Firmalar ülkelerin içerisine yuvalanarak ikinci düzeyi, zaman ise firmaların içerisine yuvalanarak son düzeyi oluşturmaktadır. Çalıșmada bağımlı değişken olarak faaliyet karlılığı (FVÖKTA) değişkeni kullanılmıştır. Bu değişken Eşitlik (1)'de verilen formül kullanılarak hesaplanmıştır.

Faaliyet Karlılığ $\iota(F V O ̈ K T A)=\frac{\text { Faiz Vergi Öncesi Karlılık }}{\text { Toplam Aktifler }}$

FVÖKTA, firma varlıklarının faaliyetlerden getiri oluşturma kapasitesini göstermektedir. Faiz vergi öncesi karın toplam aktiflere bölünmesi elde edilen oranda faiz vergi öncesi kar, firmaların brüt karından operasyonel giderlerinin çıkarılması ile bulunur. Bu oran, firmaların dönemler itibariyle operasyonel performanslarını ölçmek için kullanılan karlılık oranıdır. Firma karlılığı çalışmalarında sıklıkla kullanılan bu kar hesaplama yöntemi sayesinde firmaların faaliyet karlılıkları doğru şekilde ölçülmüştür (Kunga - Wen, 2007; Aytürk ve Yanık, 2015; Wang, 2002)

Bağımlı değişkene ait tanımlayıcı istatistikler Tablo 1'de verilmiştir. Çalışmaya dâhil edilen ülkelerin ortalama faaliyet karlılıklarının -0.20 ile 0.18 arasında değiștiği görülmektedir. Örneklem periyodundaki faaliyet karlılığının ortalaması ise yaklaşık 0.05 olarak hesaplanmıştır. Bu değer çalışma kapsamındaki firmaların ortalama faiz ve vergi öncesi karının(zararının) toplam aktiflerin \%5'i kadar olduğunu göstermektedir. En yüksek ortalama faaliyet karlılığına sahip ülke 0.18 ile Zambiya olurken en düşük oran ise -0.20 ile Filipinler'deki firmaların ortalaması olmuştur. 
Türkiye'nin faaliyet karlılığı ortalaması ise 0.05 olduğu görülmektedir. Ülkelerin faiz, vergi ve muhasebe politikaları gibi uygulamaları birbirinden farlılı gösterdiğinden getiri potansiyelleri de birbirinden olmaktadır. Filipinler'de faaliyet gösteren firmaların faaliyet karlılığı göstergesinin standart sapması en büyük (10.02) olduğundan en çok değişkenliği bu ülkedeki firmalar göstermektedir.

Tablo 1: Faaliyet karlılığının ülke bazında tanımlayıcı istatistikleri

\begin{tabular}{|c|c|c|c|}
\hline Ülke & Ortalama & Standart Sapma & Firma Sayısı \\
\hline Bangladeş (BGD) & 0.09 & 0.077 & 1750 \\
\hline Bulgaristan (BGR) & 0.05 & 0.093 & 611 \\
\hline Brezilya (BRA) & 0.019 & 1.186 & 3772 \\
\hline Botsvana (BWA) & 0.152 & 0.13 & 150 \\
\hline Çin (CHN) & 0.027 & 4.605 & 39106 \\
\hline Kolombiya (COL) & 0.072 & 0.085 & 446 \\
\hline Ekvador (ECU) & 0.172 & 0.097 & 29 \\
\hline Gana (GHA) & 0.116 & 0.113 & 149 \\
\hline Endonezya (IDN) & 0.069 & 0.128 & 4856 \\
\hline Hindistan (IND) & 0.059 & 0.137 & 40149 \\
\hline Jamaika (JAM) & 0.134 & 0.195 & 276 \\
\hline Ürdün (JOR) & 0.02 & 0.109 & 1452 \\
\hline Kazakistan (KAZ) & 0.093 & 0.119 & 226 \\
\hline Kenya (KEN) & 0.093 & 0.129 & 451 \\
\hline Lübnan (LBN) & 0.112 & 0.058 & 37 \\
\hline Sri Lanka (LKA) & 0.07 & 0.111 & 2568 \\
\hline Fas (MAR) & 0.102 & 0.088 & 771 \\
\hline Meksika (MEX) & 0.079 & 0.073 & 1358 \\
\hline Mauritius (MUS) & 0.058 & 0.082 & 378 \\
\hline Malezya (MYS) & 0.034 & 0.241 & 11447 \\
\hline Namibya (NAM) & 0.095 & 0.112 & 57 \\
\hline Nijerya (NGA) & 0.076 & 0.121 & 1084 \\
\hline Pakistan (PAK) & 0.087 & 0.115 & 3782 \\
\hline Peru (PER) & 0.105 & 0.142 & 1138 \\
\hline Filipinler (PHL) & -0.195 & 10.023 & 2331 \\
\hline Papua Yeni Gine (PNG) & -0.01 & 0.182 & 88 \\
\hline Romanya (ROU) & 0.031 & 0.236 & 1503 \\
\hline Rusya (RUS) & 0.072 & 0.174 & 3032 \\
\hline Sudan (SDN) & 0.04 & 0.061 & 14 \\
\hline Sirbistan (SRB) & 0.067 & 0.087 & 159 \\
\hline Esvatini (SWZ) & 0.025 & 0.06 & 5 \\
\hline Tayland (THA) & 0.06 & 0.15 & 6873 \\
\hline Tunus (TUN) & 0.068 & 0.083 & 521 \\
\hline Türkiye (TUR) & 0.051 & 0.11 & 3730 \\
\hline Ukrayna (UKR) & 0.081 & 0.128 & 221 \\
\hline Venezuela (VEN) & 0.05 & 0.092 & 132 \\
\hline Vietnam (VNM) & 0.09 & 0.096 & 4642 \\
\hline Güney Afrika (ZAF) & 0.083 & 0.211 & 3279 \\
\hline Zambiya (ZMB) & 0.176 & 0.198 & 154 \\
\hline Ortalama/Toplam & 0.047 & 2.739 & 142727 \\
\hline
\end{tabular}


Çalışmaya dâhil edilen bağımsız değişkenler net işletme sermayesi oranı ( $N$ İS), alacak devir hızı $(A L D H)$, stok devir hızı $(S D H)$, borç devir hızı $(B D H)$, cari oran $(C O)$, varlık yapısı $(V Y)$, kaldıraç oranı $(K O)$, aktif devir hızı $(A K D H)$, öz sermaye devir hızı (ÖZDH) ve firma büyüklüğü $(F B)$ olmuştur. Firma büyüklüğü değişkeni dışındaki bütün değişkenler, oran olarak hesaplanmıştır. Firma büyüklüğü değişkeni hesaplanırken, firmaların toplam varlıklarının doğal logaritması kullanılmıştır. Bağımsız değişkenlere ait açıklamalar Tablo 2'de verilmiştir.

Tablo 2: Bağımsız değişkenlerin açıklamaları

\begin{tabular}{|c|c|}
\hline Net İşletme Sermayesi Oranı ( $\boldsymbol{N}$ IS $)$ & (Cari Varlıklar - Cari Yükümlülükler)/(Toplam Aktifler) \\
\hline Alacak Devir Hızı ( $\boldsymbol{A} \boldsymbol{L D} \boldsymbol{H})$ & Satışlar /Ortalama Ticari Alacaklar \\
\hline Stok Devir Hızı ( $\boldsymbol{S} \boldsymbol{D} \boldsymbol{H})$ & Satılan Malın Maliyeti /Ortalama Stoklar \\
\hline Borç Devir Hızı ( $\boldsymbol{B D H})$, & Satılan Malın Maliyeti /Ortalama Ticari Borçlar \\
\hline Cari Oran $(\boldsymbol{C O})$, & Cari Varlıklar/Cari Yükümlülükler \\
\hline Varlık Yapısı (VY), & Sabit Varlıklar/Toplam Aktifler \\
\hline Kaldıraç Oranı $(\boldsymbol{K O})$ & Toplam Borç/(Toplam Borç + Öz Sermayenin Piyasa Değeri) \\
\hline Aktif Devir Hızı ( $\boldsymbol{A} \boldsymbol{K} \boldsymbol{D} \boldsymbol{H})$ & Satışlar / Toplam Aktifler \\
\hline Öz Sermaye Devir Hızı (ÖZDH) & Satışlar / Öz Sermayenin Piyasa Değeri \\
\hline Firma Büyüklüğü $(\boldsymbol{F} \boldsymbol{B})$ & Toplam Varlıkların Doğal Logaritması \\
\hline
\end{tabular}

Veri setinde yer alan firmaya özgü değişkenler araştırmaya dâhil edilen ülkelerdeki firmalar için her yıl farklı değerler almaktadır. Kullanılan bağımsız değişkenlerde ülkeden ülkeye ve zamana göre değişerek değer almaktadırlar. Çalışmada kullanılan bağımsız değişkenlere ait tanımlayıcı istatistikler ve değişkenler arasındaki korelasyonlar ise sırası ile Tablo 3 ve Tablo 4'de verilmiştir.

Tablo 3: Bağımsız değişkenlerin tanımlayıcı istatistikleri

\begin{tabular}{|l|c|c|c|c|c|c|c|c|c|c|}
\hline & $\begin{array}{c}\text { Net } \\
\text { Issletme } \\
\text { Sermaye } \\
\text { Oranı }\end{array}$ & $\begin{array}{c}\text { Alacak } \\
\text { Devir } \\
\text { Hızı }\end{array}$ & $\begin{array}{c}\text { Stok } \\
\text { Devir } \\
\text { Hızı }\end{array}$ & $\begin{array}{c}\text { Borç } \\
\text { Devir } \\
\text { Hızı }\end{array}$ & $\begin{array}{c}\text { Cari } \\
\text { Oran }\end{array}$ & $\begin{array}{c}\text { Varlık } \\
\text { Yapıs }\end{array}$ & $\begin{array}{c}\text { Kaldıraç } \\
\text { Oranı }\end{array}$ & $\begin{array}{c}\text { Aktif } \\
\text { Devir } \\
\text { Hızı }\end{array}$ & $\begin{array}{c}\text { Öz } \\
\text { sermaye } \\
\text { Devir } \\
\text { Hızı }\end{array}$ & $\begin{array}{c}\text { Firma } \\
\text { Büyüklüğ̈ }\end{array}$ \\
\hline Ortalama & 0.003 & 67.83 & 310.7 & 95.14 & 432 & 0.331 & 0.269 & 0.893 & 3.277 & 7.345 \\
\hline Medyan & 0.16 & 9.21 & 8.18 & 10.9 & 1.49 & 0.3 & 0.21 & 0.72 & 1.34 & 7.18 \\
\hline Std. Sapma & 33.08 & 6581 & 29585 & 6922 & 112393 & 0.229 & 1.729 & 1.121 & 73.809 & 2.836 \\
\hline N & $\mathbf{1 4 2 7 2 7}$ & $\mathbf{1 4 0 9 8 8}$ & $\mathbf{1 3 1 2 1 9}$ & $\mathbf{1 3 7 1 5 0}$ & $\mathbf{1 4 2 6 6 2}$ & $\mathbf{1 4 2 7 2 7}$ & $\mathbf{1 4 2 7 2 7}$ & $\mathbf{1 4 2 7 2 7}$ & $\mathbf{9 7 5 0 3}$ & $\mathbf{1 3 9 7 8 2}$ \\
\hline
\end{tabular}


Tablo 4: Değișkenler arasındaki korelasyonlar

\begin{tabular}{|c|c|c|c|c|c|c|c|c|c|c|c|}
\hline & $\begin{array}{l}\text { Faaliyet } \\
\text { Karlılığ }\end{array}$ & $\begin{array}{l}\text { Net } \\
\text { İşletme } \\
\text { Sermaye } \\
\text { Oranı } \\
\end{array}$ & $\begin{array}{l}\text { Alacak } \\
\text { Devir } \\
\text { Hizı }\end{array}$ & $\begin{array}{l}\text { Stok } \\
\text { Devir } \\
\text { Hizl }\end{array}$ & $\begin{array}{l}\text { Borç } \\
\text { Devir } \\
\text { Hizı }\end{array}$ & $\begin{array}{l}\text { Cari } \\
\text { Oran }\end{array}$ & $\begin{array}{l}\text { Varlık } \\
\text { Yapısı }\end{array}$ & $\begin{array}{l}\text { Kaldıraç } \\
\text { Oranı }\end{array}$ & $\begin{array}{l}\text { Aktif } \\
\text { Devir } \\
\text { Hızı }\end{array}$ & $\begin{array}{l}\text { Öz } \\
\text { sermaye } \\
\text { Devir } \\
\text { Hızı } \\
\end{array}$ & $\begin{array}{l}\text { Firma } \\
\text { Büyüklüğü }\end{array}$ \\
\hline $\begin{array}{l}\text { Faaliyet } \\
\text { Karlılığı }\end{array}$ & 1.00 & & & & & & & & & & \\
\hline $\begin{array}{l}\text { Net } \\
\text { İşletme } \\
\text { Sermaye } \\
\text { Oranı }\end{array}$ & 0.20 & 1.00 & & & & & & & & & \\
\hline $\begin{array}{l}\text { Alacak } \\
\text { Devir Hızı }\end{array}$ & 0.00 & -0.01 & 1.00 & & & & & & & & \\
\hline $\begin{array}{l}\text { Stok Devir } \\
\text { Hızı }\end{array}$ & 0.00 & 0.00 & 0.00 & 1.00 & & & & & & & \\
\hline $\begin{array}{l}\text { Borç Devir } \\
\text { Hızı }\end{array}$ & -0.01 & 0.00 & 0.00 & 0.00 & 1.00 & & & & & & \\
\hline Cari Oran & -0.01 & 0.08 & 0.00 & 0.00 & 0.00 & 1.00 & & & & & \\
\hline $\begin{array}{l}\text { Varlık } \\
\text { Yapısı }\end{array}$ & -0.03 & -0.53 & 0.00 & -0.01 & -0.01 & -0.03 & 1.00 & & & & \\
\hline $\begin{array}{l}\text { Kaldıraç } \\
\text { Oranı }\end{array}$ & -0.15 & -0.55 & 0.00 & -0.01 & 0.00 & -0.04 & 0.29 & 1.00 & & & \\
\hline $\begin{array}{l}\text { Aktif Devir } \\
\text { Hızı }\end{array}$ & 0.14 & 0.02 & 0.02 & 0.01 & 0.02 & -0.01 & -0.12 & -0.02 & 1.00 & & \\
\hline $\begin{array}{l}\text { Öz } \\
\text { sermaye } \\
\text { Devir Hızl }\end{array}$ & -0.02 & -0.03 & 0.00 & 0.00 & 0.01 & 0.00 & -0.01 & 0.03 & 0.07 & 1.00 & \\
\hline $\begin{array}{l}\text { Firma } \\
\text { Büyüklüğü }\end{array}$ & 0.20 & -0.16 & 0.00 & 0.01 & 0.00 & -0.04 & 0.05 & 0.17 & 0.18 & 0.01 & 1.00 \\
\hline
\end{tabular}

\subsection{Ekonometrik Metot: Hiyerarşik Lineer Model (HLM)}

Hiyerarşik bir yapıda birimler içinde yer aldığı gruplardan, gruplar da kendilerini oluşturan birimlerden etkilenirler. Birimler ve gruplar arasındaki bu karşılıklı etkileşimin analizlerde dikkate alınması gerekir. Birimler ve bu birimlerden oluşan gruplar hiyerarşik bir yapı oluşturur. Bu yapının analizinde, kullanılan değişkenler grup ve birim değişkenleri olarak farklı düzeylere ayrılabilir (Toraman vd., 2018). Hiyerarşik bir veri seti yapısı gereği gruplara ayrılmış olduğunda hata terimlerinin ilişkisizliği varsayımı sağlanamayabilir. Bu problemi çözmek için, gruplara ait kukla değişkenleri kullanılarak genişletilen Araç Değişkenli En Küçük Kareler yöntemi kullanılabilir. Ancak grup sayısı fazla olduğunda bu yöntem serbestlik derecesinin düşmesine neden olmaktadır. Diğer bir yol ise, kukla değişkenler yerine grup etkisini ölçebilen açıklayıcı değişkenlerin modele dâhil edilmesidir. Fakat grup etkilerini ölçebilen değişkenleri saptamak mümkün olmayabilir. Grup etkilerinin dikkate alınmadığı durumlarda birinci tür hatanın yapılma olasılığı artar. Diğer bir ifade ile gruplar arasında değişkenlik yokken var olduğu kabul edilebilir (Goldstein, 2011).

Hiyerarşik lineer modelleme (HLM) grup düzeylerinin bağımlı değişkene etkisinin ve gruplar arası değişkenlik ile birlikte incelemesine olanak tanır. Yatay ve zaman kesitlerinin birleșmesi ile oluşan panel veri seti iki aşamalı çok düzeyli bir model için uygun bir yapıya sahiptir. Zaman boyutu birinci 
düzeyi, yatay kesitte yer alan birimler ise ikinci düzeyi oluşturur. Yatay kesitte yer alan birimlerinde kendi aralarında gruplanması ile model üç düzeyli bir yapıya dönüşür. Birinci düzeydeki zaman boyutunu oluşturan dönemlerin kronolojik olarak sıralı olması gerekir. HLM tahmincisinin panel veri setlerinde kullanılmasının avantajlarından biri de bağımlı ve bağımsız değişkenlerde kayıp verilerin olmasına olanak tanımasıdır. Ancak veri setindeki dengesizliğin rassal olması gerekir. Bu modellerin tahminlerde MAR varsayımının geçerli olması ile en çok olabilirlik (maximum likelihood) metoduyla tutarlı tahminler yapılabilir (Skrondal ve Rabe-Hesketh, 2008). Hiyerarşik lineer model yaklaşımında varyans bileșenleri, rassal sabit ve rassal eğim modeli olarak üç temel model tahmin edilebilir.

\section{ANALIZ}

\subsection{Varyans Bileşenleri Modeli}

İlk olarak varyans bileşenleri modeli tahmin edilerek çoklu yapının ülke, firma ve zaman düzeylerinin faaliyet karlılığı üzerindeki etkisi ayrıştırılmıştır.

$F V O ̈ K T A_{i j k}=\beta_{0,0 \mathrm{jk}}+e_{i j k}$

$e_{i j k} \sim N\left(0, \sigma_{e}^{2}\right)$

Modelde FVÖKTA $A_{i j k}$ k'inci ülkedeki, j'inci firmanın i'inci yıla ait faaliyet karlılığı oranıdır. $\beta_{0,0 j k}$ ise k'inci ülkedeki, j'inci firmanın örneklem periyoduna ait faaliyet karlılığının ortalamasını ifade eder. Rassal hata terimi $\left(\mathrm{e}_{\mathrm{ijk}}\right)$ ise zaman düzeyindeki varyansı ifade etmektedir.

$F V O ̈ K T A_{i j k}=\beta_{0,0 \mathrm{jk}}+e_{i j k}$

$\beta_{0,0 \mathrm{jk}}=\beta_{0,00 \mathrm{k}}+u_{0 j k}$

$u_{0 j k} \sim N\left(0, \sigma_{u}^{2}\right)$

Eşitlik (3)'de firma ortalaması olan $\beta_{0,0 j k}$, ikiye ayrılır. $\beta_{0,00 k}$ k'inci ülkenin ortalamasını, $u_{o j k}$ ise firmalar arasındaki değişkenliği göstermektedir.

$F V O ̈ K T A_{i j k}=\beta_{0,00 \mathrm{k}}+u_{0 j k}+e_{i j k}$

$\beta_{0,00 \mathrm{k}}=\beta_{0,000}+v_{00 k}$

$v_{00 k} \sim N\left(0, \sigma_{v}^{2}\right)$

Ülke ortalaması $\left(\beta_{0,00 \mathrm{k}}\right)$, tüm örneklem ortalaması $\left(\beta_{0,000}\right)$ ile ülkeler arasındaki değişkenliği gösteren rassal hata terimi ( $\mathrm{v}_{00 \mathrm{k}}$ ) olmak üzere iki kısımdan oluşur. Üç düzeyli varyans bileşenleri modeli ise kurulan modellerin bileşimi ile elde edilmiștir:

$F V O ̈ K T A_{i j k}=\beta_{0,000}+v_{00 k}+u_{0 j k}+e_{i j k}$

$e_{i j k} \sim N\left(0, \sigma_{e}^{2}\right)$

$u_{0 j k} \sim N\left(0, \sigma_{u}^{2}\right)$

$v_{00 k} \sim N\left(0, \sigma_{v}^{2}\right)$

Model varyansının ne kadarının gruplar arasındaki varyansdan oluştuğunu tespit etmek için Varyans Parçalama Katsayısı (VPC) kullanılabilir. Gruplar arası farklılık olup olmadığı tespit etmek için aşağıdaki formül kullanılabilir. Gruplar arası farklılık olup olmadığı tespit etmek için aşağıdaki formül kullanılır (Steele, 2008).

$V P C=\frac{\sigma_{u}^{2}}{\sigma_{u}^{2}+\sigma_{e}^{2}}$ 
İlk model olan varyans bileşenleri analizinin sonuçları Tablo 5'nin birinci bölümünde verilmiştir. Faaliyet karlılığındaki ülkeler arasındaki değișkenlik 0.245, aynı ülkedeki firmalar arası değișkenlik ise 22.494 şeklinde gözlemlenmiştir. Tablonun ikinci bölümünde, modelin varyansının ne kadarının düzeyler arasındaki değişkenliğini gösteren varyans parçalama katsayıları verilmiştir. Faaliyet karlılığındaki değişkenliğin \%97.6'sı zaman düzeyinden, firmaya özgü değişkenliğin faaliyet karlılığı üzerindeki etkisinin ise \%2.4 olduğu tespit edilmiştir. Ülkeler arasındaki farklılıktan kaynaklanan kısmı \%0.03 olarak hesaplanmıştır.

Tablo 5: Faaliyet karlılığındaki değişkenliğin varyans bileșenleri analizi

\begin{tabular}{|c|c|c|c|c|}
\hline \multicolumn{5}{|c|}{ 1.Bölüm: Katsayılar (Standart Hatalar) } \\
\hline & Varyans Bileșenleri Modeli & & Sabit Mo & \\
\hline & Model 1 & Model 2 & Model 3 & Model 4 \\
\hline \multirow{2}{*}{ Ülke Düzeyi } & 0.25 & 0.00 & 0.00 & 0.00 \\
\hline & -0.22 & 0.00 & 0.00 & 0.00 \\
\hline \multirow{2}{*}{ Firma Düzeyi } & 22.49 & 0.00 & 0.01 & 0.01 \\
\hline & -26.81 & 0.00 & 0.00 & 0.00 \\
\hline \multirow[b]{2}{*}{ Zaman Düzeyi } & 919.45 & 0.00 & 0.01 & 0.01 \\
\hline & -973.80 & 0.00 & 0.00 & 0.00 \\
\hline \multicolumn{5}{|c|}{ 2. Bölüm: Varyans Parçalama Katsayıları (VPC) } \\
\hline & Model 1 & Model 2 & Model 3 & Model 4 \\
\hline Ülke Düzeyi & $0.03 \%$ & $11.72 \%$ & $7.32 \%$ & $7.81 \%$ \\
\hline Firma Düzeyi & $2.39 \%$ & $43.40 \%$ & $43.24 \%$ & $43.14 \%$ \\
\hline Zaman Düzeyi & $97.59 \%$ & $44.88 \%$ & $49.44 \%$ & $49.05 \%$ \\
\hline
\end{tabular}

Not: Katsayılara ait test istatistiklerinin p-değerleri parantez içerisinde verilmiştir.

Bu sonuçlarına göre, firmaların faaliyet karlılığındaki farklılaşmanın büyük bir kısmının firma ve zaman düzeylerinden kaynaklandığı görülmektedir. Ülke düzeylerindeki değişkenlik ise oldukça azdır. Ancak faaliyet karlılığı üzerinde ülke düzeyinin etkisinin tamamen olmadığını söylenemez. Model 4'de görüldüğü gibi açıklayıcı değişkenlerin de eklenmesiyle düzeydeki değişimde artış olmaktadır. Ülkeye özgü açıklayıcı değişkenlerin yer aldığı Model 4'e baktığımızda ülke düzeyine ait VPC \%7.81 olduğu görülmektedir. Bu oranlar hiyerarşik bir modelin gerekli olduğunu ortaya koymaktadır.

\subsection{Rassal Sabit Modeli}

Faaliyet karlılığı değişkeninin varyans bileșenleri ayrıştırıldıktan sonra Model 1'e ait denkleme açıklayıcı değişkenlerin de eklenmesiyle Eşitlik (7)'deki rassal sabit modeli elde edilmiştir.

$F V O ̈ K T A_{i j k}=\beta_{000}+\sum_{m=1}^{M} \beta_{m, 000} \sum_{m=1}^{M} X_{m, i j k}+u_{0 j k}+e_{i j k}$ 
Modelde $X_{m, i j k}$, k'inci ülkede faaliyet gösteren j'inci firmanın, m'inci bağımsız değişkeninin i'inci yılda aldığı değerdir. $\beta_{m, 000}$ ise m'inci firmaya ait açıklayıcı değişkenin katsayısıdır. Faaliyet karlılığını etkileyen faktörleri saptamak için backward iteration yöntemi kullanılmıştır. Bu yöntemde tüm değişkenlerin içerdiği orijinal veri setinden bağımlı değişkeni açıklamayanlar aşamalı olarak elimine edilerek en uygun model belirlenmektedir. Rassal sabit modellerinin tahmin sonuçları Tablo 6'de yer almaktadır.

Tablo 6: Rassal sabit terim ile HLM analiz sonuçları

\begin{tabular}{|c|c|c|c|}
\hline & \multicolumn{3}{|c|}{ Faaliyet Karlılığı } \\
\hline & Model 2 & Model 3 & Model 4 \\
\hline Nís & $\begin{array}{c}0.078^{* * *} \\
(0.011)\end{array}$ & $\begin{array}{c}0.088^{* * *} \\
(0.012)\end{array}$ & $\begin{array}{c}0.088^{* * *} \\
(0.013)\end{array}$ \\
\hline ALDH & $\begin{array}{l}0.000^{* *} \\
(0.000)\end{array}$ & $\begin{array}{c}0.000^{* * *} \\
(0.000)\end{array}$ & $\begin{array}{l}0.000^{* *} \\
(0.000)\end{array}$ \\
\hline SDH & $\begin{array}{c}0.000 \\
(0.000)\end{array}$ & & \\
\hline BDH & $\begin{array}{c}0.000^{* * *} \\
(0.000)\end{array}$ & $\begin{array}{c}0.000^{* * *} \\
(0.000)\end{array}$ & $\begin{array}{c}0.000^{* * *} \\
(0.000)\end{array}$ \\
\hline $\mathrm{CO}$ & $\begin{array}{c}0.000 \\
(0.000)\end{array}$ & $\begin{array}{c}0.000^{* * *} \\
(0.000)\end{array}$ & $\begin{array}{l}0.000^{* *} \\
(0.000)\end{array}$ \\
\hline VY & $\begin{array}{c}0.028^{* * *} \\
(0.005)\end{array}$ & $\begin{array}{c}0.035^{* * *} \\
(0.007)\end{array}$ & $\begin{array}{c}0.033^{* * *} \\
(0.009)\end{array}$ \\
\hline KO & $\begin{array}{c}-0.049^{* * *} \\
(0.005)\end{array}$ & $\begin{array}{c}-0.048^{* * *} \\
(0.006)\end{array}$ & $\begin{array}{c}-0.049^{* * *} \\
(0.005)\end{array}$ \\
\hline AKDH & $\begin{array}{c}0.006 \\
(0.005)\end{array}$ & $\begin{array}{c}0.005 \\
(0.005)\end{array}$ & \\
\hline ÖZDH & $\begin{array}{l}0.000^{* *} \\
(0.000)\end{array}$ & $\begin{array}{l}0.000^{* *} \\
(0.000)\end{array}$ & $\begin{array}{c}0.000^{* * *} \\
(0.000)\end{array}$ \\
\hline FB & $\begin{array}{c}0.013^{* * *} \\
(0.003)\end{array}$ & $\begin{array}{c}0.014^{* * *} \\
(0.003)\end{array}$ & $\begin{array}{c}0.015^{* * *} \\
(0.003)\end{array}$ \\
\hline Sabit Terim & $\begin{array}{l}-0.043^{* *} \\
(0.022)\end{array}$ & $\begin{array}{c}-0.056^{* * *} \\
(0.023)\end{array}$ & $\begin{array}{c}-0.055^{* *} \\
(0.024)\end{array}$ \\
\hline \multicolumn{4}{|c|}{ Varyans Bileşenleri Modeli } \\
\hline Ülke Düzeyi & $\begin{array}{c}0.001 \\
(0.000)\end{array}$ & $\begin{array}{c}0.001 \\
(0.000)\end{array}$ & $\begin{array}{c}0.001 \\
(0.000)\end{array}$ \\
\hline Firma Düzeyi & $\begin{array}{c}0.004 \\
(0.001)\end{array}$ & $\begin{array}{c}0.007 \\
(0.003)\end{array}$ & $\begin{array}{c}0.007 \\
(0.003)\end{array}$ \\
\hline Zaman Düzeyi & $\begin{array}{c}0.004 \\
(0.000)\end{array}$ & $\begin{array}{c}0.008 \\
(0.002)\end{array}$ & $\begin{array}{c}0.008 \\
(0.002)\end{array}$ \\
\hline
\end{tabular}

Not: Asimptotik standart hatalar katsayıların altında parantez içerisinde verilmiştir. ${ }^{* * *} \% 1, * * \% 5$ ve * \%10 düzeyinde istatistiki anlamlılık göstergesidir. 
Tablo 6'de görüldüğü gibi stok devir hızı, cari oran ve aktif devir hızı değişkenleri ile faaliyet karlılığı arasında anlamlı bir ilişkiye rastlanmamıștır. Stok devir hızı değişkeninin modelden 2'den çıkarılması ile Model 3 elde edilmiştir. Model 3'de görüldüğü gibi stok devir hızının elimine edilmesi ile faaliyet karlılığı ile borç ödeme gücü göstergesi olan cari oran ile ilişkinin anlamlı hale geldiği görülmektedir. Aktif devir hızı ile faaliyet karlılığı arasında anlamlı bir ilişki görülmediğinden aktif devir hızı değişkeninin Model 3'den çıkarılması sonucunda Model 4 elde edilmiştir.

Son olarak aktif devir hızı değişkeninin Model 3'den çıkarılması sonucunda Model 4 elde edilmiştir. Bu modelde Padachi (2006), Şahin (2011), Korkmaz, Karaca (2014) ve Raheman vd. (2010) bulguları ile uyumlu olarak firmaların net işletme sermayesi oranı ile karlılığı arasında pozitif anlamlı bir etkinin olduğu görülmektedir. Firmalar cari varlıklarını arttırdıklarında, yani ihtiyatlı işletme sermayesi stratejisi uyguladıklarında faaliyet karlılığının da artacağı saptanmıştır. Nakit satışların haricinde firmaların en önemli para giriş kaynaklarından birisi de alacak devir hızıdır. Coşkun ve Kök (2011)'ün çalışmasında ifade edildiği gibi alacak devir hızının yüksek olduğu firmaların karlılığının daha yüksek olduğu ortaya konmuştur. Analiz sonuçlarına göre firmaların borç devir hızı arttığında faaliyet karlılığı da artmaktadır. Ancak bu ilişkinin ekonomik anlamlılığı çok düşüktür. Literatürdeki çalışmaların çoğunda borç devir hızı ile karlılık arasında ters yönlü bir ilişki ortaya gözlemlenmiştir (Öz ve Güngör, 2007; Aygün, 2012; Padachi, 2006).

Firmaların kaldıraç oranı ile karlılıkları arasında beklenildiği gibi negatif bir ilişki olduğu görülmektedir. Çalışma sonucunda düşük kaldıraç oranına sahip olan firmaların faaliyet karlılığının yüksek olduğu saptanmıştır. Nitekim Çakır, Küçükkaplan (2012), Özçalık, Aytekin (2017), Korkmaz ve Karaca (2014) benzer bulgulara ulaşmışlardır. Daha önceki yapılan çalışmalarla uyumlu olarak firmaların büyüklüğü ile karlılıkları arasında pozitif anlamlı bir etki bulunmuştur (Yazdanfar ve Öhman, 2014; Deloof, 2003).

\section{SONUÇ}

Bu çalışmada, net çalışma sermayesinin firma karlılığı üzerindeki etkisi analiz edilmiştir. Uygulama aşamasında gelişmekte olan ülkelerde faaliyet gösteren halka açık firmaların net işletme sermayesi yönetiminin ve firma karlılığı ile ilişkisi araştırılmıştır. 2005-2018 yıllarında gelişmekte olan 39 ülkede faaliyet gösteren 142727 halka açık firmanın verileri ile net işletme sermayesi yönetiminin firma karlılığı üzerindeki etkisi firma, ülke ve zaman düzeyinde HLM yaklaşımı kullanılarak incelenmiştir. Analiz sonucunda firma karlılığındaki değișkenliğin büyük bir kısmının firma ve zaman düzeylerinden kaynaklandığı ortaya konmuştur. Ancak ülke düzeyindeki değişkenliğin küçük olması ülkeye özgü değişkenliğin firma karlılığı üzerinde etkisinin olmadığı șeklinde yorumlanmamalıdır. Modele açıklayıcı değişkenlerin eklenmesi ile ülke düzeyindeki değişkenliğin karlılık üzerindeki etkisinin arttığı gözlemlenmiştir. Sonuç olarak zaman ve firma düzeylerindeki değişkenliğin karlılık üzerinde daha çok etkisi olduğu söylenebilir. Analiz sonuçlarına göre firmalar net işletme sermayelerini arttırdıklarında faaliyet karlılıklarının da doğrusal olarak artacağı ortaya konmuştur. İhtiyatlı net işletme sermayesi stratejisi uygulayan firmaların faaliyet karlılığının artacağı saptanmiştır.

Aynı zamanda alacak devir hızı, cari oran, varlık yapısı, öz sermaye devir hızı ve firma büyüklügü ile karlılık arasında pozitif ilişki bulunmuştur. Cari oran kısa vadeli borç ödeme gücünün bir göstergesidir. Borç ödeme gücü arttıkça firmaların faaliyet karlılığının da artacağı söylenebilir. Cari oranın düşük olduğu firmalar yeni finansman kaynaklarını bulmakta zorlanırken, bu oranın yüksek olduğu firmalarda likiditenin iyi değerlendirilemediği söylenebilir. Çalışmada ticari borç devir hızı ile karlılık arasında negatif yönlü bir ilişki beklenirken pozitif yönlü bir ilişkinin olduğu gözlemlenmiştir. Finansal sıkıntı derecesi düşük olan firmaların ticari kredilerin devir hızındaki artışı karlılığı da arttırabileceği söylenebilir. Ancak giderek borç devir hızını arttıran firmaların uzun vadede karlılıkları olumsuz etkilenecektir. 
Ayrıca kaldıraç oranını azaltan firmaların karlarının arttığı gözlemlenmiştir. Ayrıca çalışmanın sonucunda, stok devir hızı ve aktif devir devir hızı katsayılarının firma karlılığı üzerinde herhangi bir etkisi olmadığı görülmüştür.

Sonuç olarak, gelişmekte olan ülkelerde faaliyet gösteren firmalarda karlılı̆̆ın, ülkeye özgü etkenlerden çok firma düzeyindeki faktörlerden etkilendiği görülmüştür. Bu nedenle kar maksimizasyonunu hedefleyen firma yöneticileri bu faktörlerin etkin yönetimine yoğunlaşmalıdır. Net işletme sermayesinin etkin yönetimi de firma karlılı̆̆ üzerinde etkilidir. 


\section{KAYNAKÇA}

Afza, T., ve Nazir, M. S. (2008). Working capital approaches and firm's returns in Pakistan. Pakistan. Journal of Commerce and Social Sciences (PJCSS), 1, 25-36.

Akbulut, R. (2011). İMKB'de imalat sektöründeki işletmelerde işletme sermayesi yönetiminin karlılık üzerindeki etkisini ölçmeye yönelik bir araștırma. İstanbul University Journal of the School of Business Administration, 40(2).

Akgüç, Ö. (2013). Finansal Yönetim. İstanbul: Avcıol Yayınevi.

Aktas, N., Croci, E., ve Petmezas, D. (2015). Is working capital management value-enhancing? Evidence from firm performance and investments. Journal of Corporate Finance, 30, 98-113.

Altaf, N., ve Shah, F. (2017). Working capital management, firm performance and financial constraints. Asia-Pacific Journal of Business Administration.

Aydın, N., Başar M. ve Coşkun M. (2015). Finansal Yönetim-I. Eskişehir: Anadolu Üniversitesi Yayınları, 3. Baskı.

Aygün, M. (2012). Firma Performansi Üzerinde Calisma Sermayesinin Etkisi: Türk İmalat Sektörü Üzerine Bir Uygulama/The Effect of Working Capital on Firm Performance: An Examination on Turkish Manufacturing Sectors. Ege Akademik Bakış, 12(2), 215.

Aytürk, Y., ve Yanik, S. (2015). Çalisma Sermayesi Yönetimi Türkiye'deki KOBI'lerde Karliligi Nasil Etkiler?/Working Capital Management How Does Profitability Affect SMEs in Turkey?. Muhasebe ve Finansman Dergisi, (68).

Baños-Caballero, S., García-Teruel, P. J., ve Martínez-Solano, P. (2014). Working capital management, corporate performance, and financial constraints. Journal of Business Research, 67(3), 332338.

Bhatia, S., ve Srivastava, A. (2016). Working capital management and firm performance in emerging economies: evidence from India. Management and Labour Studies, 41(2), 71-87.

Bhunia, A., ve Das, A. (2015). Underlying relationship between working capital management and profitability of pharmaceutical companies in India. American Journal Of Theoretical and Applied Business, 1(1), 27-36.

Block, Stanley. B. ve Hirt, Geoffrey. A. (2005). Foundations of Financial Management. New York: McGraw- Hill Companies, 11th Edition.

Brigham E. F., Houston J. F., ve Western S. (2016). Finansal Yönetimin Temelleri - Fundamentals of Financial Management. Çev. Cantürk Kayahan vd. Ankara: Nobel Akademik Yayıncılık, 7. Baskı.

Coşkun, E., ve Kök, D. (2011). Çalışma sermayesi politikalarının karlılık üzerine etkisi: dinamik panel uygulaması. Ege Akademik Bakış, 11, 75-85.

Çakır, H. M. (2013), Nakit Döngüsünün Firma Kârlılığına Etkisinin Sektörel Analizi. Journal of Yaşar University, 30/8, 4948-4965.

Çakır, H. M., ve Küçükkaplan, İ. (2012). İşletme sermayesi unsurlarının firma değeri ve karlılığı üzerindeki etkisinin İMKB'de işlem gören üretim firmalarında 2000-2009 dönemi için analizi. Muhasebe ve Finansman Dergisi, (53), 69-86.

Dağlı, H. (2013), Finansal Yönetim. 1 Cilt. Trabzon: Derya Kitapevi. 
Deloof, M. (2003). Does working capital management affect profitability of Belgian firms?. Journal of Business Finance ve Accounting, 30(3-4), 573-588.

Demireli, E., Başcl, E. S., ve Karaca, S. S. (2014). İşletme sermayesi ve performans göstergeleri arasındaki ilişkiler: Borsa İstanbul üzerine bir uygulama. Ege Stratejik Araştırmalar Dergisi, 5(1), 79-98.

Doğan, M. ve Elitaș, B. L. (2014). Çalışma Sermayesi Gereksiniminin Belirleyicileri: Borsa İstanbul Gıda Sektörü Üzerine Bir İnceleme. World of Accounting Science, 16/2, 1-15.

Goldstein, H. (2011). Multilevel Statistical Models. 4 B. London: Wiley.

Jose, M. L., Lancaster, C., ve Stevens, J. L. (1996). Corporate returns and cash conversion cycles. Journal of Economics And Finance, 20(1), 33.

Kindik, N. ve Aslan, A.(2017). Kârlılık Sürdürülebilirliği Ve Kârlılı̆̆ı Etkileyen Faktörlerin Analizi: Bir Kooperatif İşletmesi Olan Konya Şeker Fabrikası. Üçüncü Sektör Sosyal Ekonomi Dergisi 52/Özel Sayı, 608-626. doi:10.15659/3.sektor-sosyal-ekonomi.17.12.833

Korkmaz, Ö., ve Karaca, S. S. (2014). Üretim işletmelerinde firma karlılığının finansal belirleyicileri ve BIST imalat sanayi uygulamasi/financial determinants of firm profitability in manufacturing firms and an application on BIST manifacturing firms. Ege Akademik Bakıș, 14(1), 21.

Korkmaz, T. ve Ceylan, A. (2011). Finansal Yönetim Temel Konular. Bursa: Ekin Basım Yayın Dağıtım, 10. Baskl.

Kung, C. Y., ve Wen, K. L. (2007). Applying grey relational analysis and grey decision-making to evaluate the relationship between company attributes and its financial performance-a case study of venture capital enterprises in Taiwan. Decision Support Systems, 43(3), 842-852.

Küçükaraba, M. (2012). Firma Değerlemesi ve İMKB Uygulaması. İstanbul: Marmara Üniversitesi, Sosyal Bilimler Enstitüsü, Yüksek Lisans Tezi.

Martin, T. K. (2013). Financial Management Principles and Applications. 12th Edition. Pearson Series in Finance.

Ng, H., Chen, Y., San Ong, T., ve Teh, B. H. (2017). The impact of working capital management on firm's profitability: Evidence from Malaysian listed manufacturing firms. International Journal of Economics and Financial Issues, 7(3), 662.

Okka, O. (2010). Finansal Yönetim Teori ve Çözümlü Problemler. Ankara: Nobel Yayın Dağıtım.

Öz, Y. ve Güngör, B. (2007). Çalışma Sermayesi Yönetiminin Firma Kârlılığı Uzerine Etkisi: İmalat Sektörüne Yönelik Panel Veri Analizi. Atatürk Üniversitesi Sosyal Bilimler Enstitüsü Dergisi 10/2, 319-332.

Özçalık, S. G. ve Aytekin, S. (2017). İşletme Değeri İle Finansal Oranlar Arasında İlişki Var Mı? Borsa İstanbul'da Bir Uygulama. Balıkesir Üniversitesi Sosyal Bilimler Enstitüsü Dergisi 20/38, 203214.

Padachi, K. (2006). Trends in working capital management and its impact on firms' performance: an analysis of Mauritian small manufacturing firms. International Review Of Business Research Papers, 2(2), 45-58.

Panigrahi, C. M. A. (2013). Negative Working Capital and Profitability: An Empirical Analysis of Indian Cement Companies. International Journal of Research in Commerce ve Management, 4(6). 
Ponsian, N., Chrispina, K., Tago, G., ve Mkiibi, H. (2014). The effect of working capital management on profitability. International Journal of Economics, Finance and Management Sciences, 2(6), 347-355.

Prasad, P., Narayanasamy, S., Paul, S., Chattopadhyay, S., ve Saravanan, P. (2019). Review of literature on working capital management and future research agenda. Journal of Economic Surveys, 33(3), 827-861.

Raheman, A., ve Nasr, M. (2007). Working capital management and profitability-case of Pakistani firms. International Review of Business Research Papers, 3(1), 279-300.

Raheman, A., Afza, T., Qayyum, A., ve Bodla, M. A. (2010). Working capital management and corporate performance of manufacturing sector in Pakistan. International Research Journal of Finance and Economics, 47(1), 156-169.

Skrondal, A., ve Rabe-Hesketh, S. (2008). Multilevel And Related Models For Longitudinal Data. In Handbook of multilevel analysis (pp. 275-299). Springer, New York, NY.

Steele, F. (2008). Module 5: Introduction to Multilevel modelling concepts. LEMMA (Learning Environment for Multilevel Methodology and Applications), Centre for Multilevel Modelling, University of Bristol.

Şahin, O. (2011). İMKB’ye Kayıtlı İmalat Şirketlerinde Çalışma Sermayesi Politikaları ve Firma Performansı İlişkileri. Eskişehir Osmangazi Üniversitesi İktisadi ve İdari Bilimler Dergisi, 6(2), 123-141.

Toraman Ç., Akay E., Özdemir H. F. ve Karadağ E. (2018). Çok Düzeyli Regresyon Modelleri HLM Uygulamaları. Ankara: Nobel Akademik Yayıncılık, 1. Baskı.

Wang, Y. J. (2002). Liquidity management, operating performance, and corporate value: evidence from Japan and Taiwan. Journal of Multinational Financial Management, 12(2), 159-169.

Yazdanfar, D., ve Öhman, P. (2014). The impact of cash conversion cycle on firm profitability. International Journal of Managerial Finance. 


\section{EXTENDED ABSTRACT}

\section{The Effect Of Net Workıng Capital Management To Profitability In Developıng Countries: Hierarchical Model Approach}

\section{Introduction}

Short-term investments and their liquidity are vital for successfully managing a firm's resources (Yazdanfar \& Ohman, 2014). Liquid assets enable companies to satisfy their short-term liabilities (Padachi, 2006). The liquidity risk, which companies bear due to their investment and financing decisions, affects profitability closely. The working capital components, their interrelatedness, and their functions in daily operations play an essential role in liquidity management. The portion of current assets financed by long-term capital constitutes net working capital. Firms that make correct net working capital investments may have the opportunity to earn higher returns by investing their excess resources in long-term assets (Okka, 2010).

This study seeks to answer the question of whether net working capital management is related to firm profitability in developing countries. Country- and firm-specific factors affecting the profitability of 142,727 companies from 39 developing countries between 2005 and 2018 were investigated using the Hierarchical Linear Model (HLM) approach.

\section{Data Set and Method}

Firm-level data of developing countries that are available in the Compustat Global Capital IQ database are used in this study. Compustat Global Capital IQ is an extensive database containing financial data of publicly traded companies operating in different countries. However, as in other global data banks, companies operating in developing countries are very few in this data set compared to developed countries. The final data set comprises 142,727 publicly traded companies from 39 developing countries. The period of the study was determined as 2005-2018 due to the inaccessibility of the data of the previous years. In addition to company-specific data drawn from the Compustat Global Capital IQ database, several country-specific variables from the World Bank's World Development Indicators dataset were also used.

The created panel data set is considered a hierarchical structure regarding countries, companies, and time levels. A three-stage multi-level (hierarchical) approach is employed to model this hierarchical structure. The first level of the model is countries. Firms create the second level by nesting inside the countries, and time forms the last level by nesting within the firms. The operating profitability variable is used as the dependent variable in the study.

\section{Empirical Findings}

The findings reveal a significant positive relationship between net working capital and profitability in developing countries. When firms increase their current assets, their operating profitability will also increase. Apart from cash sales, one of the most important sources of money entry for companies is receivable turnover. The companies with a high receivable turnover rate are more profitable.

There is not any significant relationship between the inventory turnover, current ratio, asset turnover, and operating profitability. When the inventory turnover is excluded from the analysis, the relationship between operating profitability and the current ratio, a solvency indicator, becomes significant. There was no meaningful relationship between asset turnover and operating profitability. According to the analysis results, when the debt turnover rate of the companies increases, the operating profitability also increases. However, the economic significance of this relationship is very low. Also, there is a negative relationship between the leverage ratio and profitability. Consistent 
with previous studies, a positive and significant relationship exists between firm size and profitability (Yazdanfar \& Öhman, 2014; Deloof, 2003).

\section{Discussion and Conclusion}

In this study, the relationship between the net working capital management and the profitability of publicly traded companies operating in developing countries was investigated. It has been revealed that a large part of the variability in firm profitability is due to firm- and time-levels. However, the smallness of the variability at the country level should not be interpreted as the fact that the countryspecific variability does not affect firm profitability. It was observed that the effect of country-level variability on profitability increased with the addition of more explanatory variables to the model. As a result, it can be said that the variability in time and firm levels have more effect on profitability. When companies increase their net working capital, their operating profitability will increase linearly.

At the same time, a positive relationship was found between receivables turnover, current ratio, asset structure, equity turnover, firm size and profitability. The current ratio is an indicator of short-term solvency. It can be said that as the solvency of debt increases, the operating profitability of the companies will also increase. Companies with a low current ratio have difficulty finding new financing resources, while companies with a high current ratio cannot make good use of liquidity. In the study, while a negative relationship is expected between commercial debt turnover and profitability, it was observed that there is a positive relationship. The increase in the turnover rate of commercial loans of companies with a low degree of financial distress can also increase profitability. However, the long-term profitability of companies that increase their debt turnover rate will be adversely affected. In addition, the inventory turnover and asset turnover coefficients do not affect the firm's profitability.

Profitability in companies operating in developing countries is affected by firm-level factors rather than country-specific factors. Effective management of net working capital also has an impact on firm profitability. For this reason, company managers aiming at profit maximization should focus on the effective management of these factors. 